\title{
Estudo comportamental de Cebus nigritus (Goldfuss, 1809) (Primates, Cebidae) em cativeiro
}

\author{
Behavioral study of Cebus nigritus (Goldfuss, 1809) \\ (Primates, Cebidae) in captivity
}

\author{
Lívia Bertolla Santos ${ }^{1}$; Nelio Roberto dos Reis ${ }^{2}$
}

\section{Resumo}

O objetivo desse estudo foi descrever as atividades comportamentais de Cebus nigritus em cativeiro. O trabalho foi realizado durante o mês de março de 2008, contando com 48 horas de observações, divididas em quatro períodos diurnos. Os locais de estudo foram o Zoológico Municipal "Dr. Belírio Guimarães Brandão", Garça - SP, e o Parque Ecológico da Fazenda Monte Alegre, Telêmaco Borba PR. O catálogo comportamental utilizado foi constituído de diferentes categorias, como: forrageamento, alimentação, locomoção, descanso, interação social, cuidados corporais, alerta, manipulação de objetos, comportamento reprodutivo e comportamento estereotipado. Os animais exibiram atividades de forrageamento, alimentação, locomoção e interação social em baixas porcentagens nos dois períodos da manhã; porém, suas freqüências aumentaram nos horários da tarde. Outras atividades como cuidados corporais, estado de alerta e comportamento estereotipado apareceram principalmente nos dois períodos da manhã; mas foram reduzidas à tarde. A categoria descanso foi mais evidente no primeiro período da manhã e no último período da tarde. Devido ao fato de o comportamento estereotipado ser recorrente, sugere-se que seja diversificado o número de indivíduos na organização social dos grupos e que sejam trabalhadas atividades de enriquecimento ambiental nos cativeiros, criando situações semelhantes às do habitat natural.

Palavras-chave: Comportamento. Cativeiro. Macaco-prego.

\begin{abstract}
The objective of this study was to describe the behavior of Cebus nigritus kept in captivity. The work, carried out during the month of March 2008 at "Dr. Belírio Guimarães Brandão" County Zoo in GarçaSP and Monte Alegre Farm Ecological Park in Telêmaco Borba- PR, included 48 hours of observations, divided equally in four daytime periods. The behavioral catalogue used was constituted of different categories such as: foraging, feeding, locomotion, rest, social interaction, physical care, alertness, manipulation of things, reproductive behavior and stereotyped behavior. Animals showed activities of foraging, feeding, and locomotion and social interaction in low percentages in the two morning periods; however, their frequencies increased in the afternoon. Other activities like physical care, alertness and stereotyped behavior appeared mainly in the two morning periods, but were reduced in the afternoon. The rest category was more evident early morning and late afternoon. Since the stereotypical behavior presented high percentages, this study recommends that the number of individuals be diversified in the social organization of the groups and that environment enriching activities be developed in captivity, creating situations similar to the animal's natural habitat.
\end{abstract}

Key words: Behavior. Captivity. Capuchin monkey.

1 Graduada em Ciências Biológicas na Universidade Estadual Paulista (UNESP), Assis - SP; Cursando Pós-graduação de Mestrado em Ciências Biológicas, área Zoologia, na Universidade Estadual de Londrina (UEL), Londrina - PR; e-mail: liviabertolla@, yahoo.com.br

2 Doutor em Ciências pelo INPA (1981); Titular da área de ecologia de mamíferos da Universidade Estadual de Londrina.; e-mail: nrreis@uel.br. 


\section{Introdução}

A etologia estuda os fenômenos ecológicos e comportamentais de organismos individuais e de populações, e muitas vezes enfatiza as diferenças entre indivíduos ou entre suas classes hierárquicas dentro de uma população (CASSINI, 1999).

O estudo do comportamento animal e o da história natural são utilizados como ferramentas básicas para a compreensão de interações ecológicas e da biodiversidade, com aplicação direta em programas de conservação (DEL-CLARO; TOREZAN-SILINGARDI, 2006). Já a pesquisa do comportamento em cativeiro visa a adequar as necessidades básicas de cada espécie em relação à alimentação, reprodução e padrões sociais, obtendose maior adaptação dos animais a esses ambientes não naturais e manejo adequado para a espécie (CARROL, 1991). O ambiente físico ao qual os animais estão submetidos na condição de cativeiro pode influenciar de forma marcante a expressão de comportamentos típicos da espécie, reforçando a importância de estudos que avaliem esse tipo de modulação (BARBOSA; MOTA, 2004).

Segundo a classificação proposta por Groves (2001), a família Cebidae pertence à infraordem Platyrrhini e é composta por três subfamílias: Cebinae, Saimirinae e Callitrichinae.

Macacos do gênero Cebus, subfamília Cebinae, são encontrados em quase toda a região neotropical (FREESE; OPENHEIMER, 1981), sendo amplamente distribuídos pela América do Sul e Central. São diurnos, arborícolas, com dieta onívora, composta principalmente por frutos, sementes, insetos, brotos e pequenos vertebrados (BICCAMARQUES; SILVA; GOMES, 2006; FRAGASZY; VISALBERGHI; FEDIGAN, 2004; LUDWIG; AGUIAR; ROCHA， 2005; VISALBERGHI; ANDERSON, 1999) Possuem cauda semipreênsil, utilizada durante o forrageio para suspensão ou apoio, e apresentam grande destreza manual (AURICCHIO, 1995).
A espécie Cebus nigritus (Goldfuss, 1809), popularmente conhecida como macaco-prego, ocorre em vários estados da região Sul e Sudeste do Brasil: Rio de Janeiro, leste de São Paulo, Paraná, Santa Catarina e Rio Grande do Sul (COIMBRAFILHO, 1990). São primatas de porte médio e corpo robusto; apresentam um tufo de pêlos eretos no alto da cabeça, semelhante a um topete, e pêlos como uma faixa branca de cada lado da face. Sua coloração pode variar do pardo muito escuro com ventre avermelhado ao negro uniforme (SILVEIRA; REIS; ROCHA, 2005). O peso médio dos indivíduos adultos é de $3,2 \mathrm{~kg}$ (machos) e $2,3 \mathrm{Kg}$ (fềmeas) (SILVEIRA; REIS, 2008).

$\mathrm{Na}$ natureza, esses animais formam grupos de 11 a 23 indivíduos, ocupando uma grande diversidade de habitats, como florestas chuvosas inundáveis, florestas primárias e secundárias, caatinga, palmeiras, campos e mangues, com áreas variando de 12 (SILVEIRA; REIS; ROCHA, 2005) a 40 hectares (FREESE; OPPENHEIMER, 1981). A espécie é conhecida por sua grande tolerância de sobrevivência em ambientes alterados pelo homem e é facilmente encontrada em fragmentos florestais no norte do Estado do Paraná, cujos patrimônios naturais vêm sofrendo intensas devastações por atividades agropecuárias (LUDWIG; AGUIAR; ROCHA, 2005). Segundo COIMBRA-FILHO (1990), C. nigritus era muito abundante, mas atualmente suas populações estão apresentando um acentuado declínio devido à fragmentação de habitats, cujas conseqüências são o isolamento da espécie e seu subseqüente declínio populacional (PAGLIA; FERNANDEZ; DE MARCO JUNIOR, 2006). LOVEJOY et al. (1986) observou que um fragmento amazônico de 100 ha não foi capaz de comportar as espécies de primatas, inclusive $C$. apella, cujos grupos apresentavam áreas de vida maiores de 100 ha. Ainda dentro do caminho da fragmentação, agrava-se o possível efeito de borda sofrido pelas espécies, que é definido como as mudanças abióticas e bióticas ocorrentes no entorno dos fragmentos florestais, podendo se estender por 
longas distâncias para seu interior (OLIFIERS; CERQUEIRA, 2006).

Diante da importância de estudos comportamentais e de suas contribuições para a conservação da espécie, o objetivo desse trabalho foi descrever as atividades comportamentais de Cebus nigritus em cativeiro.

\section{Metodologia}

Áreas de estudo

A Fazenda Monte Alegre da Empresa Klabin S/A está localizada nas coordenadas $24^{\circ} 12^{\prime} 42^{\prime \prime S ~ e ~}$ 50³3'26'W, na cidade de Telêmaco Borba, região do médio Tibagi, centro-leste do estado do Paraná (REIS; PERACCHI; PEDRO; LIMA, 2002). Possui uma área de 126.737 hectares e altitude média de 885 m. O clima da região, segundo Köppen, é do tipo subtropical, com temperaturas médias de $16,3^{\circ} \mathrm{C}$ no inverno e $23,2^{\circ} \mathrm{C}$ no verão, e a média anual de precipitação é de $1.478 \mathrm{~mm}$ (REIS; PERACCHI; FANDIÑO-MARIÑO; ROCHA, 2005). A fazenda contém um Parque Ecológico que ocupa uma área de 11.196 ha, dos quais 7.883 ha são compostos por florestas naturais. Este parque possui um Criadouro Científico de animais silvestres, registrado junto ao IBAMA, que é utilizado para aulas de Educação Ambiental. Ele é constituído por 53 recintos e viveiros que abrigam 18 espécies de mamíferos, 48 espécies de aves e algumas serpentes. No caso da reprodução em cativeiro, é executado o programa de reintrodução de espécies da fauna silvestres já extintas na região. O Criadouro propicia condições de tratamento a animais silvestres apreendidos pela fiscalização, com atendimento veterinário, alimentação e reaclimatação, permitindo sua reintrodução à vida silvestre.

Quanto às instalações, na Fazenda Monte Alegre existem três recintos com a espécie estudada. Um deles contém três indivíduos (um macho adulto, um macho subadulto e uma fêmea adulta), o outro contém seis indivíduos machos (dois adultos, um subadulto, um juvenil e um infante), e o último possui quatro indivíduos machos (um adulto, dois subadultos e um juvenil). Os recintos medem, aproximadamente, $30 \mathrm{~m}^{2}$ por $2 \mathrm{~m}$ de altura e seus cambiamentos de manejo medem cerca de $2 \mathrm{~m}^{2}$ por $2 \mathrm{~m}$ de altura. Os ambientes dos cativeiros estão compostos por vários troncos de madeira, permitindo a utilização de todos os estratos (solo, baixo, médio e alto) pelos animais, um abrigo de madeira suspenso e uma bacia de concreto com fornecimento de água constante. A alimentação, composta por grande variedade de frutas e verduras, era fornecida duas vezes ao dia: no período da manhã (entre 8 e 9 h) e no período da tarde (entre 15 e $16 \mathrm{~h})$.

O município de Garça situa-se na região CentroOeste do Estado de São Paulo, nas coordenadas $22^{\circ} 12^{\prime} 55^{\prime}$ 'S e 49³9'04'W. A cidade possui uma área total de $554 \mathrm{Km}^{2}$, com altitude média de $683 \mathrm{~m}$. O clima é do tipo Subtropical, com temperatura máxima de $28,5^{\circ} \mathrm{C}$ e mínima de $17,8^{\circ} \mathrm{C}$, e precipitação média anual de $1.274 \mathrm{~mm}$ (CITY BRASIL, 2008). O Bosque e Zoológico Municipal "Dr. Belírio Guimarães Brandão" está localizado dentro da cidade, apresentando uma área de 18,50 hectares de Mata Atlântica preservada. $\mathrm{O}$ criadouro abriga, atualmente, cinco espécies de aves, oito espécies de mamíferos e quatro espécies de répteis. Existe apenas um recinto com Cebus nigritus, composto por um macho subadulto e uma fêmea adulta. $\mathrm{O}$ viveiro mede aproximadamente $15 \mathrm{~m}^{2}$ por $2 \mathrm{~m}$ de altura e seu cambiamento em torno de $2 \mathrm{~m}^{2}$. Alguns troncos, galhos e plataforma compõem o ambiente. Os animais são alimentados no período da manhã com frutas, verduras e pão molhado com leite próprio para bezerros e, no período da tarde, recebem maior quantidade de frutas e verduras. Ovos e alguns tipos de carne crua são fornecidos semanalmente.

\section{Registros comportamentais}

O trabalho foi realizado durante o mês de março de 2008, contando com quatro dias de observações 
comportamentais, divididos nos períodos das 6 às $9 \mathrm{~h}$, das 9 às $12 \mathrm{~h}$, das 12 às $15 \mathrm{~h}$ e das 15 às $18 \mathrm{~h}$. O local de estudo para os períodos da manhã foi o Zoológico Municipal de Garça, e, para os períodos da tarde, foi o Parque da Fazenda Monte Alegre.

O método de amostragem utilizado durante as observações foi o Scan sampling (ALTMANN, 1974; SETZ, 1991) com intervalos de 5 minutos, que consiste na observação e registro de um único comportamento de cada indivíduo do grupo a cada intervalo de tempo.

Durante as sessões de coletas de dados, o observador permanecia sempre no mesmo local, evitando o contato visual direto com os animais. A cada sessão de observação, foram anotados: hora, classe sexo-etária do indivíduo e o comportamento executado por ele.

A estrutura do etograma, adaptada às características da espécie estudada, seguiu alguns modelos existentes (ALBUQUERQUE; CODENOTTI, 2006; MOTTA; REIS, 2008; PINTO, 2006; SERBENA; MONTEIRO-FILHO, 2002). Foram descritas diferentes categorias comportamentais, agrupadas nas seguintes classes:

1) Forrageamento: atividade relacionada à procura por alimento, geralmente de fonte animal, entre troncos, galhos, folhas ou no solo. Exemplos: lamber folhas para ingerir ovos de insetos ou larvas, cavar solo à procura de insetos ou outros invertebrados, colocar a mão em um buraco no tronco ou no solo e lambê-la.

2) Alimentação: comportamento do animal em relação a algum item alimentar seguido de ingestão. Exemplos: bater alimento com as mãos, provar alimento e ingerir.

3) Locomoção: deslocamento do animal (andar, saltar, correr, trepar e descer) desacompanhado de qualquer outra atividade.
4) Descanso: comportamento que não envolve deslocamento nem outra atividade aparente: sentar, deitar e dormir.

5) Interação Social: atividade claramente direcionada a outros membros do grupo. Podem ser afiliativas (catar, brincar, agrupar e comportamento parental) ou agonísticas (ameaçar e atacar).

6) Cuidados Corporais: comportamento do animal envolvido em sua própria pelagem (autocatação) ou em outra parte do corpo (limpar nariz e limpar ânus).

7) Estado de Alerta: atos relacionados com a captação de informações sobre o ambiente (vigiar e aproximar-se).

8) Manipulação de objetos: atividade em que o animal segura ou coloca na boca determinados objetos, sem intenção de alimentação.

9) Comportamento Estereotipado: movimentos repetitivos executados pelo animal, sem nenhuma função aparente (andar em círculos ou andar de um lado para outro).

10) Comportamento Reprodutivo: atividade relacionada à cópula propriamente dita ou à tentativa de cópula.

11) Outros: atividades que não se ajustama quaisquer das categorias anteriormente mencionadas.

Os resultados foram calculados de acordo com a freqüência de cada categoria comportamental dentre o total de registros obtidos, e divididos entre os quatro períodos diurnos. Para comparar as freqüências entre os períodos de estudo foi utilizado o teste estatístico ANOVA, utilizando o nível de significância $\mathrm{p}<0,05$.

\section{Resultados}

Nesse estudo, obtiveram-se 1645 registros em 576 sessões de amostragem, totalizando 48 horas de observações. 


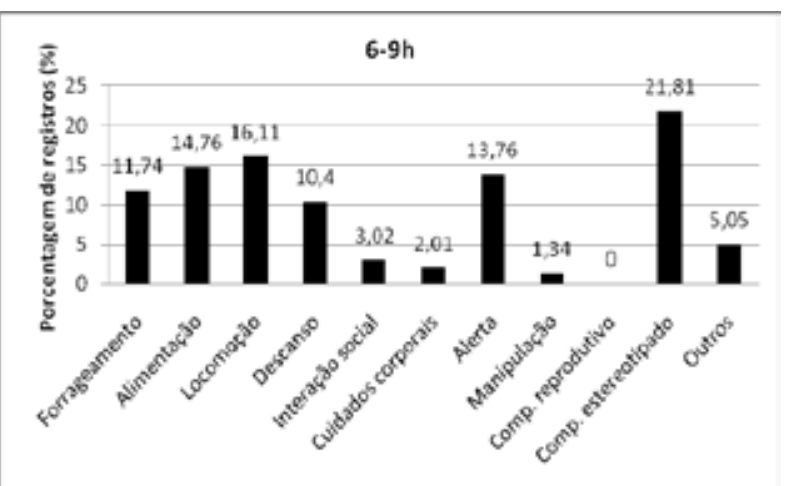

Figura 1. Porcentagens de registros das classes comportamentais exibidas pelos animais no período das 6 às $9 \mathrm{~h}$.

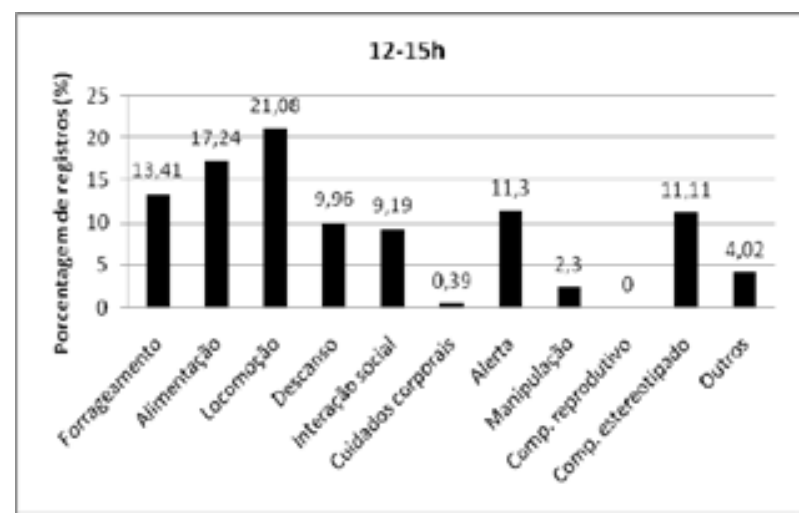

Figura 3. Porcentagens de registros das classes comportamentais exibidas pelos animais no período das 12 às $15 \mathrm{~h}$.

O comportamento de forrageio teve um aumento gradual entre os períodos, mas não significativo ( $>0$,05). Por outro lado, a alimentação aumentou significativamente $(\mathrm{p}<0,05)$ a partir das $9 \mathrm{~h}$, chegando a representar a principal atividade dos animais das 15 às $18 \mathrm{~h}$.

Os dados coletados quanto à locomoção apresentaram diferenças estatísticas $(p=0,022)$ e demonstraram que os animais realizaram essa atividade com mais intensidade à tarde. No entanto, com diferenças não significativas $(p>0,05)$, o descanso foi maior no período das 6 às $9 \mathrm{~h}$ e no das 15 às $18 \mathrm{~h}$.

As atividades relacionadas aos cuidados corporais reduziram, não significativamente $(\mathrm{p}>0,05)$, a partir

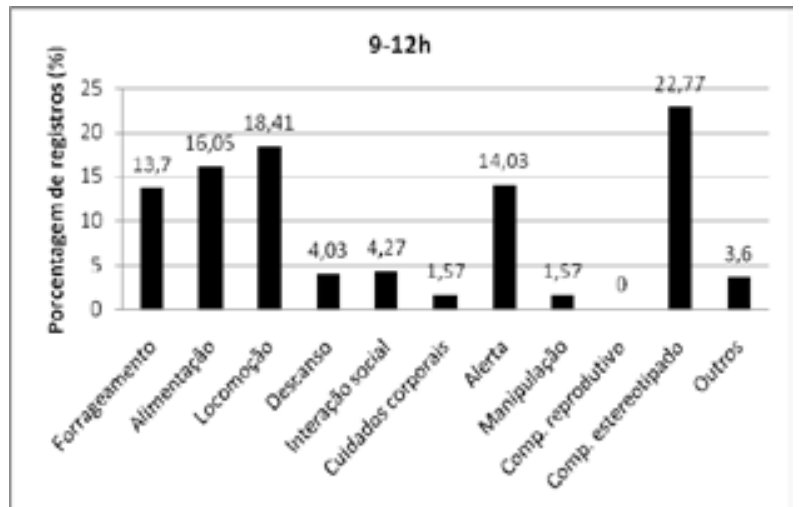

Figura 2. Porcentagens de registros das classes comportamentais exibidas pelos animais no período das 9 às $12 \mathrm{~h}$.

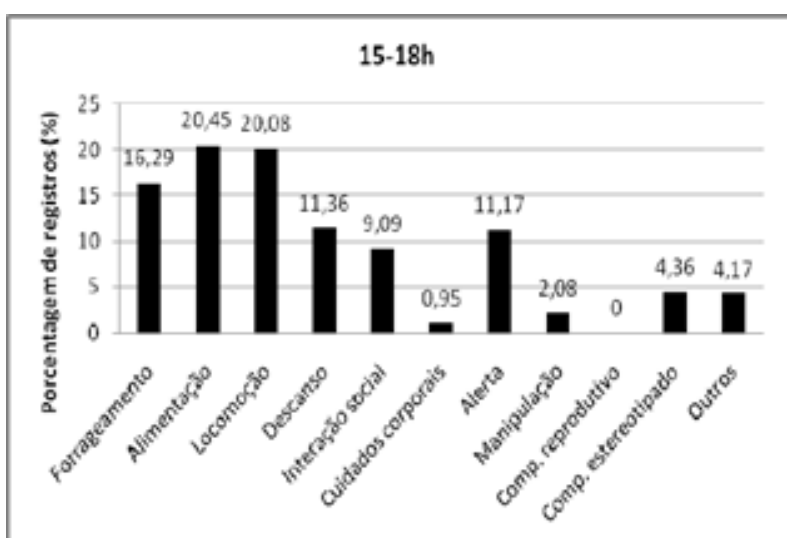

Figura 4. Porcentagens de registros das classes comportamentais exibidas pelos animais no período das $15 \mathrm{~h}$ às $18 \mathrm{~h}$.

das $9 \mathrm{~h}$, chegando a porcentagens reduzidas no período da tarde. Já o comportamento de alerta, apresentou valores altos e semelhantes em todos os períodos $(\mathrm{p}>0,05)$.

A manipulação de objetos esteve presente em baixas porcentagens, apresentando seu valor máximo das 12 às $15 \mathrm{~h}$, no entanto, as diferenças desses valores não foram significativas $(p>0,05)$. E o comportamento reprodutivo não foi constatado nenhuma vez durante as sessões de amostragem.

O comportamento estereotipado foi o mais representativo durante os períodos da manhã, no entanto, suas porcentagens tiveram reduções não significativas $(\mathrm{p}>0,05)$ até o fim do dia. 
O comportamento social, embora tenha se mantido em baixas porcentagens, apresentou um aumento relativo, porém não significativo ( $\mathrm{p}>0.05)$, das 12 às $15 \mathrm{~h}$. Dentre ele, as interações agonísticas foram praticamente insignificantes, aparecendo apenas durante a tarde e em baixas freqüências. Já as interações afiliativas tiveram total representação durante a manhã, mas reduziram sua freqüência em $18,75 \%$ até o fim do dia (Figura 5).

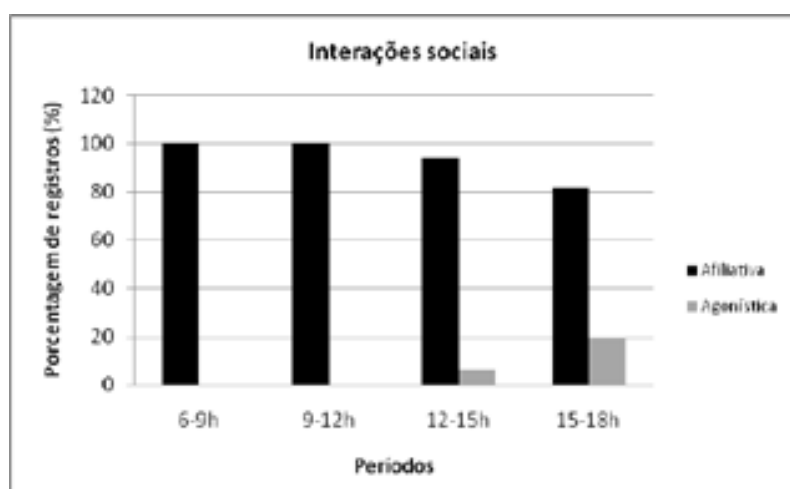

Figura 5. Porcentagem de registros das interações sociais exibidas pelos animais nos quatro períodos de observações.

\section{Discussão}

Conforme relatado para animais silvestres (CAMAROTTI; MONTEIRO-DA-CRUZ, 1997) e para animais em cativeiro (SOUZA; PONTES, 2008), seria esperado que o forrageamento (procura por insetos ou outros invertebrados) fosse maior durante as primeiras horas do dia, quando a temperatura ambiente fosse menor e os animais pudessem estar mais ativos e em maior procura por comida. No entanto, neste estudo, essa atividade, demonstrada principalmente pela procura por minhocas, foi mais significativa no segundo período da manhã e no segundo período da tarde, coincidindo com os horários logo após o fornecimento de alimento. Isso pode ser explicado pela pequena quantidade de proteína contida diariamente na alimentação e, sendo essa substância de extrema importância para a nutrição dos animais, estes precisariam forragear mais para ingerir melhores fontes protéicas.
A busca por alimento é uma atividade indispensável na vida dos primatas e influencia todas suas atividades, por isso, os animais devem estar envolvidos na maior parte do seu período de atividade na procura e ingestão de alimentos (MARTINS, 2007). Nesse trabalho, a alimentação foi, obviamente, mais freqüente no segundo período da tarde, momento em que a comida era fornecida. Os animais preferiram se alimentar assim que recebiam o alimento, provavelmente, devido à existência da competição entre os membros do grupo.

O esperado seria que os animais, como no ambiente natural, tivessem maior porcentagem de locomoção no período da manhã, quando estariam mais ativos e em maior procura por comida (N.R. REIS, observação pessoal). No entanto, os animais em cativeiro se locomoveram mais à tarde, e isso pode estar relacionado à elevada freqüência do comportamento estereotipado durante a manhã que, provavelmente, estaria substituindo a locomoção de forma não natural.

A alta freqüência do comportamento de descanso observada difere do padrão de atividades dos animais de vida livre, os quais passam grande parte do seu dia alimentando-se e locomovendo-se entre as áreas de alimentação (VAN ROOSMALEN; KLEIN, 1988). Segundo AZEVEDO e BICCA-MARQUES (2003), esta diferença comportamental é resultante do estilo de vida sedentário dos animais em cativeiro por limitações de espaço físico e pelo fornecimento regular de alimento em horários pré-estabelecidos. Os animais apresentaram maiores taxas de descanso nas primeiras horas da manhã, após o despertar, e no último período da tarde, antecedendo o recolhimento dos grupos; coincidindo com os resultados do estudo de grupos naturais de Callithrix jacchus por Camarotti e Monteiro-da-Cruz (1997). A taxa elevada dessa atividade no período matutino pode ser explicada pelo fato dos animais, nesse momento, dedicarem menos tempo para a maioria das outras atividades, ao passo que, a alta porcentagem de descanso no fim da tarde pode indicar que eles tenham realizado pequenos intervalos de descanso 
entre atividades muito representativas nesse horário (alimentação, forrageamento e locomoção). Presume-se que a freqüência desse comportamento aumentaria à medida que fossem bem sucedidos no forrageamento.

As interações sociais apresentaram baixas porcentagens, o que já era esperado, devido ao fato da formação dos grupos em cada recinto ter sido realizada pelo homem, mas nanatureza, esse processo aconteceria de forma natural e de acordo com graus de parentesco entre eles. A baixa freqüência desse comportamento pode ser resultado de um ambiente físico pobre(recintos pequenos epouco enriquecidos) abrigando os animais (SCHOENFELD, 1989). Além disso, como salientaram LI e ROGERS (2004) com Trachypithecus leucocephalus, o tamanho do grupo está positivamente correlacionado com o tempo de interações afiliativas e, por serem essas atividades as mais representativas dentre o comportamento social, o número reduzido de indivíduos estaria afetando de maneira geral a socialidade dos grupos. As porcentagens da interação social foram mais altas durante a tarde, o que, provavelmente, indica que estavam acompanhando os intervalos de descanso mencionados anteriormente.

Dentre o comportamento social, as interações agonísticas foram pouco freqüentes, mesmo sendo C. nigritus uma espécie tão agressiva (N.R. REIS observação pessoal), e ocorreram principalmente no final do dia, quando os animais já estavam alimentados e começando a reduzir suas atividades. Os animais preferem fazer ameaças claras e compreendidas por todos os indivíduos do grupo social antes de partir para um ato agonístico danoso (ALBUQUERQUE; CODENOTTI, 2006). Na maioria das vezes, o conflito ocorreu na forma de ameaça do macho adulto em direção ao macho mais velho dos grupos, possivelmente com a finalidade de disputa territorial ou defesa de indivíduos jovens por machos subadultos, pois, normalmente, essas interações surgiam após a aproximação do macho mais velho a um indivíduo jovem ou vice-versa.
As interações afiliativas fazem parte do contexto social dos primatas, auxiliando o desenvolvimento social e estreitando laços familiares (RESENDE; OTTONI, 2002). Embora os animais em cativeiro não tivessem nenhum grau de parentesco uns com os outros, essas atividades representaram a maior parte dos comportamentos sociais registrados. Sua maior freqüência durante a manhã indica que, nesse momento, os indivíduos do grupo poderiam despender mais tempo nesse tipo de comportamento, já que estavam menos envolvidos com as atividades de alimentação, forrageamento e locomoção. Dentre os comportamentos sociais afiliativos, salientou-se a brincadeira, contando sempre com a participação de pelo menos um indivíduo jovem junto com machos mais velhos, confirmando que o comportamento de brincadeira está particularmente associado a indivíduos juvenis, por facilitar o desenvolvimento social, estimular a aprendizagem e treinar as habilidades motoras (LEWIS, 2000).

Os comportamentos relacionados aos cuidados corporais foram pouco expressivos de forma geral. Seu valor máximo esteve presente das 6 às $9 \mathrm{~h}$, provavelmente devido às menores porcentagens de atividades mais intensas nesse momento, de forma que os animais pudessem despender mais tempo cuidando do seu próprio corpo.

O comportamento de alerta se mostra como uma forma de o animal poder explorar o ambiente e tomar conhecimento de algum evento ocorrido no mesmo. Segundo SERBENAe MONTEIRO-FILHO (2002), a postura do animal durante o alerta pode ser uma forma de comunicação e serve para atrair a atenção dos outros membros do grupo para algum acontecimento. $\mathrm{O}$ estado de alerta esteve presente em porcentagens relativamente altas e semelhantes entre os períodos, o que pode estar relacionado com a constante movimentação de pessoas no criadouro e, também, com a menor capacidade do animal fugir ou se esconder nesse ambiente, quando ele é ameaçado. 
A manipulação de objetos, sem intenção de alimentação, tem função de exploração do ambiente e serve como aprendizado para os jovens na utilização de ferramentas (RESENDE; OTTONI, 2002). Essa atividade foi realizada quase sempre por animais jovens ou infantes, e foi observada poucas vezes durante os períodos amostrais; o que, certamente, está relacionado com o pequeno número de indivíduos dessa faixa etária nos recintos.

O comportamento reprodutivo não foi observado durante os períodos amostrais. Isso é explicado pela presença apenas de indivíduos machos em dois dos recintos observados, enquanto nos recintos em que havia uma fêmea, talvez, a cópula não tenha ocorrido por motivos sociais do grupo formado, ou por a fêmea não estar no período fértil, quando ocorre maior parte das cópulas (WALLEN, 2001). No entanto, algumas tentativas de cópula foram observadas fora dos períodos amostrais, mas sempre ocorrendo entre dois machos, o que sugere dominância do indivíduo mais velho sobre o mais jovem.

O comportamento estereotipado é comum de ser executado por animais em cativeiro e, nesse estudo, ele se mostrou em altas porcentagens. A esse respeito, Kitchen e Martin (1996) mostraram que, para a espécie C. jacchus, animais ocupando gaiolas menores e menos enriquecidas eram menos ativos e apresentavam mais comportamento estereotipado. Por essa atividade ser mais freqüente de manhã, quando os animais estavam se alimentando e forrageando menos, pode-se dizer que, nesse período, os animais destinaram seu tempo, principalmente, para as atividades de movimento mais intenso, alterando a forma natural de locomoção.

$\mathrm{O}$ fato do comportamento estereotipado apresentar altas porcentagens neste estudo indica um alto nível de estresse dos animais, Por isso, sugere-se que seja aumentado e diversificado o número de indivíduos na organização social dos grupos, ampliando a quantidade de indivíduos jovens, já que eles estimulam a interação social, e intensificando o número de fêmeas para melhorar o comportamento reprodutivo dos grupos, desde que houvesse condições de vasectomização dos machos. Além disso, poderiam ser trabalhadas atividades de enriquecimento ambiental nos cativeiros, criando situações e ambientes semelhantes às do habitat natural.

Por causa do contínuo crescimento do processo de fragmentação de habitats, que vem ameaçando seriamente a biodiversidade global, torna-se preocupante seus efeitos deletérios sobre as populações de Cebus nigritus e, cada vez mais necessários estudos relacionados à conservação da espécie e de toda a biodiversidade.

\section{Agradecimentos}

Agradecemos à empresa Klabin e ao Zoológico Municipal "Dr. Belírio Guimarães Brandão" e aos seus respectivos funcionários por nos ter cedido espaço para a realização do trabalho e por toda a atenção a nós dedicada.

\section{Referências}

ALBUQUERQUE, V. J.; CODENOTTI, T. L. Etograma de um grupo de bugios-pretos, Alouatta caraya (Humboldt, 1812) (Primates, Atelidae) em um habitat fragmentado. Revista de Etologia, São Paulo, v. 8, n. 2, p. 97-107, 2006.

ALTMANN, J. Observational study of behavior: sampling methods. Behaviour, Leiden, v. 49, n. 3, p. 227 267, 1974.

AURICCHIO, P. Primatas do Brasil. São Paulo: Terra Brasilis, 1995.

AZEVEDO, R. B.; BICCA-MARQUES, J. C. Termorregulação comportamental em macacos-aranha Ateles chamek (Primates, Atelidae) em cativeiro. Biociências, Porto Alegre, v. 11, n. 2, p. 159-166, 2003.

BARBOSA, M. N.; MOTA, M. T. S. A influência da rotina de manejo na interação social entre pares heterosexuais do sagüi, Callithrix jacchus (Linnaeus,1758). Revista Brasileira de Zoociências, Juiz de Fora, v. 6, n. 1, p. 2943, 2004. 
BICCA-MARQUES, J. C.; SILVA, V. M.; GOMES, D. F. Ordem primates. In: REIS, N. R.; PERACCHI, A. L.; PEDRO, W. A.; LIMA, I. P. (Org.). Mamíferos do Brasil. Curitiba: Gráfica Oficial do Estado do Paraná e Sociedade Brasileira de Zoologia, 2006. p. 101-148.

CAMAROTTI, F. L. M.; MONTEIRO-DA-CRUZ, M. A. O. Fatores ecológicos e comportamentais implicados na seleção e uso dos locais de pernoite de grupos de Callithrix jacchus em ambiente natural. In: SOUZA, M. B. C.; MENEZES, A. A. L. (Org.). A primatologia no Brasil 6. Natal: EDURN, 1997. p 27-42.

CARROL, J. B. The captive breeding of the genus Callithrix at the Jersey Wildlife Preservation Trust. In: RYLANDS, A. B.; BERNARDES, A. T. (Ed.). $A$ primatologia no Brasil. Belo Horizonte: Fundação Biodiversitas, 1991. 3 v. p. 17-23.

CASSINI, M. H. Importancia de la etología en la Conservación. Etología, Luján,v. 7, n. 1, p. 69-75, 1999.

CITY BRASIL WEB SITE. Garça: dados gerais. Disponivel em: <http:/www.citybrazil.com.br/sp/garca/ geral.htm>. Acesso em: 4 jun. 2008.

COIMBRA-FILHO, A. F. Sistemática, distribuição geográfica e situação atual dos símios brasileiros (Platyrrhini-Primates). Revista Brasileira de Biologia, Rio de Janeiro, v. 50, n. 4, p. 1063-1079, 1990.

DEL-CLARO, K.; TOREZAN-SILINGARDI, H. M. Comportamento Animal, Interações Ecológicas e Conservação. In: Rocha, C. F. D.; Bergallo, H. G.; Sluys, M. V.; Alves, M. A. S. (Ed.). Biologia da conservação essências. São Carlos: Rima, 2006. p. 399-410.

FRAGASZY, D. M.; VISALBERGHI, E.; FEDIGAN, L. M. The complete Capuchin: the biology of Genus Cebus. Cambridge: Cambridge University Press, 2004.

FREESE, C. H.; OPPENHEIMER, J. R. The capuchin monkeys, genus Cebus. In: COIMBRA-FILHO, A. F.; MITTERMEIER, R. A. (Ed.). Ecology and behavior of neotropical primates. Rio de Janeiro: Academia Brasileira de Ciências, 1981. p. 331-389.

GROVES, C. P. Primate taxonomy. Washington: Smithsonian Institution Press, 2001.

KITCHEN, A. M.; MARTIN, A. A. The effects of cage size and complexity on the behaviour of captive common marmosets. Callithrix jacchus jacchus. Laboratory Animal Science, Memphis, v. 30, n. 4, p. 317-326, 1996.

LEWIS, K. P. A comparative study of primate play behaviour: implications for the study of cognition. Folia Primatologica, Basel, v. 71, n. 6, p. 417-421, 2000.
LI, Z.; ROGERS, E. Habitat quality and activity budgets of white-headed langurs in Fusui, China. International Journal of Primatology, New York, v. 25, n. 1, p. 41-54, 2004.

LOVEJOY, T. E.; BIERREGAARD, R. O.; RYLANDS, A. B.; MALCOLM, J. R.; QUINTELA, C. E.; HARPER, L. H.; BROWN, K. S. JR.; POWELL, A. H.; POWELL, G. V. N.; SCHUBART, H. O. R.; HAYS, M. B. Edge and others effects of isolation on Amazon forest fragment. In: SOULÉ, M. E. (Ed.). Extinctions. Chicago: University Press Chicago, 1986. p. 257-285.

LUDWIG, G.; AGUIAR, L. M.; ROCHA, V. J. Uma Avaliação da dieta, da área de vida e das estimativas populacionais de Cebus nigritus (Goldfuss , 1809) em um fragmento florestal no norte do estado do Paraná. Neotropical Primates, Belo Horizonte, v. 13, n. 3, p. 12$18,2005$.

MARTINS, I. G. Padrão de atividades do sagüi Callithrix jacchus numa área de Caatinga. 2007. Dissertação (Mestrado em Psicobiologia) - Universidade Federal do Rio Grande do Norte, Natal.

MOTTA, M. C.; REIS, N. R. Elaboração de um catálogo comportamental de "gato-do-mato-pequeno", Leopardus tigrinus (Schreber, 1775) (Mammalia, Carnivora, Felidae) em cativeiro. In: REIS, N. R.; PERACCHI, A. L.; DOS SANTOS, G. A. D. Ecologia de mamíferos. Londrina: Technical Books, 2008. p. 79-91.

OLIFIERS, N.; CERQUEIRA, R. Fragmentação de habitat: efeitos históricos e ecológicos. In: RochA, C. F. D.; BERGALLO, H. G.; SLUYS, M. V.; ALVES, M. A. S. Biologia da conservação essências. São Carlos: Rima, 2006. p. 261-279.

PAGLIA, A. P.; FERNANDEZ, F. A. S.; DE MARCO JUNIOR., P. Efeitos da fragmentação de habitats: quantas espécies, quantas populações, quantos indivíduos, e serão eles suficientes?. In: ROCHA, C. F. D.; BERGALLO, H. G.; SLUYS, M. V.; ALVES, M. A. S. Biologia da conservação essências. São Carlos: Rima, 2006. p. 280316.

PINTO, M. C. M. Padrão comportamental de um grupo de macacos-prego (Cebus apella cay Illiger, 1815) no Parque Estadual Matas do Segredo, Campo Grande, MS. 2006. Dissertação (Mestrado) - Universidade Federal de Mato Grosso do Sul, Campo Grande.

REIS, N. R.; PERACCHI, A. L.; PEDRO, W. A.; LIMA, I. P. Morcegos da bacia do rio Tibagi. In: MEDRI, M. E.; BIANCHINI, E.; SHIBATTA, O. A.; PIMENTA, J. A. (Ed.). A bacia do Rio Tibagi. Londrina: M.E. MEDRI, 2002. p. 251-270. 
REIS, N. R.; PERACCHI, A. L.; FANDIÑO-MARIÑO, H.; ROCHA, V. J. Mamíferos da Fazenda Monte Alegre - Paraná. Londrina: EDUEL, 2005.

RESENDE, B. D.; OTTONI, E. B. Brincadeira e aprendizagem do uso de ferramentas por macacos-prego (Cebus apella). Estudos de Psicologia, Natal, v. 7, n. 1, p. 173-180, 2002.

SCHOENFELD, D. Effects of environmental impoverishment on the social behavior of marmosets (Callithrix jacchus). American Journal of Primatology Supplement, New York, v. 1, p. 45-51. 1989. Suplemento.

SERBENA, A. L.; MONTEIRO-FILHO, E. L. A. A behavioral description of captive young capuchin monkey (Cebus apella). Revista de Etologia, São Paulo, v. 4, n.2, p. 109-116, 2002.

SETZ,E.Z.F.Métodos dequantificaçãode comportamento de primatas em estudos de campo. In: RYLANDS, A. B.; BERNARDES, A. T. (Ed.). A primatologia no Brasil, 3. Belo Horizonte: Sociedade Brasileira de Primatologia, 1991. p. 411-435.

SILVEIRA, G.; REIS, N. R. Análise das três dimensões do nicho (alimento, espaço e tempo) de Cebus nigritus (Goldfuss, 1809) (Mammalia, Primates, Cebidae) em um fragmento florestal de Londrina, Paraná, Brasil. In: REIS, N. R.; PERACCHI, A. L.; DOS SANTOS, G. A. D. Ecologia de mamíferos. Londrina: Technical Books Ed, 2008. p. 69-78.
SILVEIRA, G.; REIS, N. R.; ROCHA, V. J. Ordem Primates, In: REIS, N. R.; PERACCHI, A. L.; FANDIÑOMARINO, H.; ROCHA, V. J. (Org.). Mamíferos da Fazenda Monte Alegre - Paraná. Londrina: EDUEL, 2005. p. 67-71.

SOUZA, M. B. C.; PONTES, M. C. Variação temporal diurna de comportamentos afiliativos de sagüi comum (Callithrixjacchus) machos vivendo em ambiente natural. Zoociências, Juiz de Fora, v. 10, n. 1, p. 7-12, 2008.

VAN ROOSMALEN, M. G. M.; KLEIN, L. L. The spider monkeys, genus Ateles. In: MITTERMEIR, R. A.; RYLANDS, A. B.; COIMBRA-FILHO, A.; FONSECA, G. A. B. (Ed.). Ecology and behavior of neotropical primates. Contagem: Littera Maciel, 1988. p. 455-537.

VISALBERGHI, E.; ANDERSON, J. R. Capuchin monkeys. In: POOLE, T. (Ed.). The universities federation for the welfare of animals handbook on the care and management of laboratory animals. Oxford: Blackwell, 1999. p. 601-610.

WALLEN, K. Sex and context: hormones and primate sexual motivation. Hormones and Behavior, New York, v. 40, n. 2, p. 339-357, 2001. 